\title{
Impaired Ability of Patients with Familial Isolated Vitamin E Deficiency To Incorporate $\alpha$-Tocopherol into Lipoproteins Secreted by the Liver
}

\author{
Maret G. Traber, " Ronald J. Sokol, Graham W. Burton, ${ }^{5}$ Keith U. Ingold, \\ Herbert J. Kayden* \\ ${ }^{*}$ Department of Medicine, New York University School of Medicine, New York 10016; ' Department of Pediatrics, Section of Pediatric \\ Gastroenterology and Nutrition, University of Colorado School of Medicine, Denver, Colorado 80262; \$Division of Chemistry, \\ National Research Council of Canada, Ottawa, Ontario, Canada K1A OR6; and "Health and Nutrition Laboratory, \\ Technical Service \& Development, Eastman Chemical Products, Inc., Kingsport, Tennessee 37662
}

\begin{abstract}
Plasma and lipoprotein $\alpha$-tocopherol concentrations of four patients with familial isolated vitamin $E$ deficiency and six control subjects were observed for $4 \mathrm{~d}$ after an oral dose $(\sim 15$ $\mathrm{mg}$ ) of $\boldsymbol{R} \boldsymbol{R} \boldsymbol{R}$ - $\alpha$-tocopheryl acetate labeled with six deuterium atoms $\left(d_{6}\right.$-tocopherol). Chylomicron $d_{6}$-tocopherol concentrations were similar in the two groups. $d_{6}$-Tocopherol concentrations of plasma, very low (VLDL), low (LDL), and high (HDL) density lipoproteins were similar in the two groups only during the first $12 \mathrm{~h}$; then these were significantly lower, and the rate of disappearance faster, in the patients. The times $\left(t_{\max }\right)$ of the maximum chylomicron $d_{6}$-tocopherol concentrations were similar for the two groups, but $t_{\max }$ values in the controls increased in the order: chylomicrons $<$ VLDL $\leq$ LDL $\sim$ HDL, while the corresponding values in the patients were similar to the chylomicron $t_{\max }$. Thus, plasma $\mathrm{d}_{\mathbf{6}}$-tocopherol in controls increased during chylomicron and VLDL catabolism, whereas in patients it increased only during chylomicron catabolism, thereby resulting in a premature and faster decline in the plasma tocopherol concentration due to a lack of $\mathbf{d}_{\mathbf{6}}$-tocopherol secretion from the liver. We suggest that these patients are lacking or have a defective liver "tocopherol binding protein" that incorporates $\alpha$-tocopherol into nascent VLDL. (J. Clin. Invest. 1990. 85:397-407.) deuterated $\alpha$-tocopherol $\bullet$ tocopherol binding protein
\end{abstract}

\section{Introduction}

Humans do not readily become vitamin $\mathrm{E}$ deficient. It has been generally accepted that the quantities of vitamin $E$ in the diet are adequate and that the vitamin $\mathrm{E}$ stores in the body are sufficient to prevent any symptoms of vitamin $\mathrm{E}$ deficiency from occurring even in the face of a prolonged absence of dietary vitamin E. However, vitamin E deficiency does occur in humans as a consequence of a variety of lipid malabsorption syndromes, most notably as a result of cholestatic liver disease in children, and in the genetic disorders, abetalipoproteinemia and homozygous hypobetalipoproteinemia (as reviewed in 1).

Address reprint requests to Dr. Traber, Department of Medicine, New York University School of Medicine, 550 First Avenue, New York, NY 10016.

Received for publication 13 December 1988 and in revised form 26 July 1989.

\section{J. Clin. Invest.}

(C) The American Society for Clinical Investigation, Inc.

$0021-9738 / 90 / 02 / 0397 / 11 \quad \$ 2.00$

Volume 85, February 1990, 397-407
From these studies it has been determined that vitamin $\mathrm{E}$ deficiency in humans causes a severe, debilitating spinocerebellar lesion. Specifically, the progressive development of ataxia and areflexia with a "dying back" of the peripheral nerves, along with spinocerebellar degeneration, are characteristic of vitamin E deficiency.

Recently, nine patients worldwide have been described who exhibit similar neurologic abnormalities and vitamin $\mathrm{E}$ deficiency, but have no evidence of fat malabsorption (2-8). These patients all have normal lipid absorption, gastrointestinal, pancreatic, and intestinal function, and lipoproteins, but when consuming a normal diet, they have exquisitely low plasma vitamin $E$ levels and develop neurologic abnormalities characteristic of vitamin $E$ deficiency. With the addition of daily vitamin E supplements (400-1,200 IU) to the diet, normal plasma vitamin E levels can be maintained and in several patients improvements in neurologic function have been reported. When vitamin E supplementation is interrupted, plasma tocopherol falls sharply to suboptimal levels.

The four patients described in this report have been extensively evaluated (8). An impairment in vibratory sensation is present in all four. Nerve damage is more severe in two of the patients who experience both truncal and limb ataxia with head titubation. The tocopherol levels in peripheral nerves were also deficient (9). Supplementation with vitamin E (800-900 IU/d of all-rac- $\alpha$-tocopheryl acetate) raised the serum tocopherol levels from almost undetectable to normal, stabilized the neurologic function in two patients and improved it in the other two. The ability of these patients to absorb tocopherol was tested using an oral dose of vitamin $E$ of $100 \mathrm{IU} / \mathrm{kg}$ of body weight (8). The increase in serum tocopherol levels in response to the test dose was not different from that of control subjects but its rate of decrease in the patients was faster than in the controls. These findings led us to conclude that there was no defect in the absorption of pharmacological doses of vitamin E. However, the absorption of dietary amounts of vitamin $\mathrm{E}$ was not measured, nor was the reason for the rapid decrease in the plasma levels of tocopherol defined.

We have recently demonstrated that the kinetics of absorption and transport of vitamin $\mathrm{E}$ in plasma lipoproteins in normal human subjects can be studied using the newly available deuterated $\alpha$-tocopherols (10). The purpose of the present work was to compare in patients and normal subjects the absorption of dietary amounts of vitamin $E$ and to follow its incorporation into plasma lipoproteins using this technique. We demonstrate that the absorption of dietary quantities of vitamin $\mathrm{E}$ by patients with "familial isolated vitamin $\mathrm{E}$ defi- 
ciency" is normal and propose a mechanism to explain its subsequent rapid decline in their plasma.

\section{Methods}

Subjects. This study was carried out with the approval of the Institutional Review Boards of New York University Medical Center and the University of Colorado School of Medicine. The ages of the subjects and the exact amount of deuterated $R R R$ - $\alpha$-tocopheryl acetate consumed are shown in Table $I$. The patients have been described in detail in a previous publication and the patient number in that publication and this one correspond to the same individual (8). Patients $1-3$ are siblings; patient 4 is unrelated to the other patients and has the most severe neurologic abnormalities (11). All four patients have normal serum cholesterol, triglyceride, and apolipoprotein B levels (Table VI, [8]). The control subjects also had normal lipid values and no abnormalities of lipoprotein metabolism.

Deuterated $\alpha$-tocopherols. The syntheses and analysis of deuterated $\alpha$-tocopherols have been described previously $(12,13) .2 R, 4^{\prime} R, 8^{\prime} R-\alpha$ $\left(5,7-\left(\mathrm{C}^{2} \mathrm{H}_{3}\right)_{2}\right)$ tocopheryl acetate $\left(\mathrm{d}_{6}-R R R-\alpha\right.$-tocopheryl acetate) was provided to the subjects as a source of hexadeuterated $\alpha$-tocopherol with natural stereochemistry. 2-ambo- $\alpha-\left(5,7,8-\left(\mathrm{C}^{2} \mathrm{H}_{3}\right)_{3}\right.$ tocopherol $\left(\mathrm{d}_{9-}\right.$ tocopherol), used as an internal standard, was added to each sample immediately before lipid extraction $(10,14)$. Because of the small doses of $\mathrm{d}_{6}-R R R$ - $\alpha$-tocopheryl acetate administered it was necessary to analyze each sample in its entirety. The lipid extracts obtained from each plasma and lipoprotein fraction were purified by passage through an analytical, high-performance, silica gel chromatography column. The amounts of $\mathrm{d}_{6^{-}}, \mathrm{d}_{9}$ - and nondeuterated $\left(\mathrm{d}_{0}\right) \alpha$-tocopherol in the collected tocopherol fraction were determined by gas chromatography/ mass spectrometry after conversion to their trimethylsilyl ethers. The absolute concentrations of $d_{0^{-}}$and $d_{6}-\alpha$-tocopherol in the original plasma and lipoprotein samples were obtained by comparing the respective peak areas with the peak area of the known amount of added $d_{9}-\alpha$-tocopherol. The minimum amount of $d_{6}$-tocopherol detectable by this method is 5 pmol. A test of the accuracy of the method was carried out by the analysis in duplicate of duplicate extracts of plasma obtained from three subjects $3 \mathrm{~d}$ after a single oral dose $(15 \mathrm{mg})$ of $\mathrm{d}_{6}$-all rac- $\alpha$-tocopheryl acetate. The concentration of $\mathrm{d}_{6}$-tocopherol in the plasma was within the range obtained in the lipoprotein fractions isolated in the present study $(\sim 0.5 \mathrm{nmol} / \mathrm{ml})$ and quadruplicate deter-

Table I. Characteristics of the Subjects and Amounts of $d_{6}$-tocopherol Administered

\begin{tabular}{ccccc}
\hline Subject No. & Dose & Age* & Weight & Sex \\
\hline & $m g$ & $y r$ & $k g$ & \\
Patients $^{\ddagger}$ & & & & \\
1 & 15.6 & 26 & 54 & F \\
2 & 16.4 & 30 & 80 & M \\
3 & 18.3 & 24 & 60 & F \\
4 & 18.4 & 34 & 49 & F \\
Controls & & & & \\
5 & 17.2 & 42 & 66 & F \\
6 & 18.3 & 25 & 54 & F \\
7 & 17.1 & 30 & 57 & F \\
8 & 20.5 & 38 & 82 & F \\
9 & 14.5 & 29 & 84 & M \\
10 & 18.8 & 37 & 70 & M
\end{tabular}

* Age at the time of this study.

‡ The patient numbers correspond to the same numbers in a previous publication describing the case histories (8). minations from the subjects resulted in a standard deviation of $<5 \%$ of the mean.

Experimental protocol. Patients discontinued supplemental vita$\min \mathrm{E}$ for $2 \mathrm{wk}$ before the study, except for patient 1 , who continued to take supplements up to the initiation of the study. After an overnight fast, the subjects (four patients and six controls) swallowed a gelatin capsule containing an exactly weighed amount of $\mathrm{d}_{6}-R R R$ - $\alpha$-tocopheryl acetate (Table I) and immediately consumed a breakfast containing $100 \mathrm{~g}$ of fat ( $52 \%$ saturated and $48 \%$ unsaturated fatty acids, with $1.04 \mathrm{mg}$ unlabeled $\alpha$-tocopherol, as estimated from dietary tables). Thereafter, subjects consumed meals of their choice ad lib. Blood samples ( $15 \mathrm{ml} /$ time point) were collected $0,3,6,9,12,24,36,48,72$, and $96 \mathrm{~h}$ after taking the $\mathrm{d}_{6}-R R R-\alpha$-tocopheryl acetate in EDTA tubes (Becton-Dickinson, Rutherford, NJ) that were protected from light. The plasma was immediately separated by centrifugation, a $1.0 \mathrm{ml}$ aliquot was frozen, and the remainder was refrigerated. After the 36and the 96-h plasma samples were isolated, the refrigerated plasma samples were shipped from Denver on wet ice by overnight freight to New York City for isolation of the lipoprotein fractions. The frozen plasma samples were stored at $-70^{\circ} \mathrm{C}$ until all of the studies were carried out, then the samples were shipped on dry ice by overnight freight to New York.

Lipoprotein isolation. Within $2 \mathrm{~d}$ of the receipt of the samples in New York, the chylomicrons and lipoproteins from all of the blood samples had been isolated, as described previously (10). Briefly, chylomicrons were isolated from duplicate samples of $1 \mathrm{ml}$ plasma, overlayered with $1 \mathrm{ml}$ saline $(0.15 \mathrm{M} \mathrm{NaCl}, 0.3 \mathrm{mM}$ EDTA, $\mathrm{pH} 7.4)$, by centrifugation for $8 \mathrm{~min}$ at $40,000 \mathrm{rpm}$ using a swinging bucket rotor (TLS 55) and a TL 100 ultracentrifuge (Beckman Instruments, Inc., Palo Alto, CA). Subsequently, the indicated lipoprotein fractions were isolated by centrifugation for $2 \mathrm{~h}$ at $100,000 \mathrm{rpm}$ using a fixed angle rotor (TLA 100.2) with sequential density changes achieved by adding solid $\mathrm{KBr}$. The density ranges used were: VLDL $d<1.006$, LDL 1.006 $<d<1.063$, and HDL $d>1.063$. The HDL were not separated from the serum proteins because the $d>1.21$ fraction contains negligible amounts of tocopherol. Immediately upon isolation the lipoprotein fractions were frozen and stored at $-70^{\circ} \mathrm{C}$. The lipoprotein fractions and the $1 \mathrm{ml}$ plasma samples were taken by courier on dry ice to the National Research Council in Ottawa, Canada for analyses of the $d_{0}$ and $\mathrm{d}_{6}$-tocopherol.

To establish that exchange of tocopherol did not occur during the period of time between blood drawing and lipoprotein isolation an in vitro experiment was carried out. Previously, it has been demonstrated that the tocopherol in the chylomicron/VLDL fraction does not readily exchange $(15,16)$, that is $\left[{ }^{3} \mathrm{H}\right]$ tocopherol remains in these triglyceride-rich lipoproteins rather than transferring to unlabeled red cells, while it readily transfers from LDL and HDL to red cells (15-17). Furthermore, the amount of chylomicrons and VLDL in normal plasma is relatively low, therefore, we focused on the ability of tocopherol to exchange between LDL and HDL. These lipoproteins were isolated from plasma from a control subject, who then consumed 50 $\mathrm{mg}$ of $\mathrm{d}_{6}-R R R$ - $\alpha$-tocopheryl acetate with breakfast. LDL and HDL were also isolated from a second blood sample drawn $24 \mathrm{~h}$ after the dose. The lipoproteins were dialyzed against saline $(0.15 \mathrm{M} \mathrm{NaCl}, 0.3$ mM EDTA, pH 7.4), then were diluted to their original concentration in plasma. $1 \mathrm{ml}$ of unlabeled LDL was incubated with $1 \mathrm{ml}$ of labeled $\mathrm{HDL}$, and vice versa, for 2 or $24 \mathrm{~h}$ at either 4 or $37^{\circ} \mathrm{C}$. The densities of the samples were raised to $1.063 \mathrm{~g} / \mathrm{ml}$ with $\mathrm{KBr}$ and the LDL and HDL were reisolated by ultracentrifugation as described above. There was no appreciable exchange of deuterated tocopherol between LDL and $\mathrm{HDL}$ at $4^{\circ} \mathrm{C}$ during a 24-h incubation. However, exchange did take place rapidly at $37^{\circ} \mathrm{C}$. (No data are shown.) This experiment emphasizes that rapid exchange of tocopherol can occur in vivo, but that the rate of exchange can be greatly retarded by cooling the samples. The tocopherol in LDL and HDL are presumed to undergo mutual exchange in vivo on a time scale that is short relative to the time intervals between the drawing of successive blood samples in this study. Once 
the blood samples had been drawn care was taken to keep the samples cold.

Computation and statistical analysis. Analysis of variance was performed using the General Linear Models (GLM) ${ }^{1}$ procedure (Statistical Analysis System [SAS] software [18]). The GLM procedure was chosen to analyze the data because it could handle the unbalanced design resulting from the unequal number of subjects in the control and patient groups and the absence of data at some time points for some individuals. Separate analyses were performed for the plasma and for each of the lipoprotein fractions. Since the same groups of individuals were tested repeatedly over the time period, comparisons were made between the patient and control groups with the time points treated as "repeated measures"; "the group by time interaction" was also computed in the model used to test whether the two groups changed differently over the entire time interval. In addition, comparisons based on least square means were performed at each of the individual time points (19). The area under the curve (AUC) of the $d_{6}$-tocopherol concentration in the plasma and each lipoprotein fraction for each subject was computed using the trapezoidal rule. The time, $t_{\max }$, at which the maximum concentration of the $d_{6}$-tocopherol in the plasma and each lipoprotein fraction for each subject occurred was computed using the pharmacokinetic model described below. The GLM procedure was also used to assess the statistical significance of the comparisons of the AUC and of the $t_{\max }$ between patients and controls.

Pharmacokinetic modeling. Pharmacokinetic modeling was based on established methods (20). The model used assumes a single open compartment with first order kinetics for the increase and decrease in the $d_{6}$-tocopherol concentrations. (First order kinetics are generally assumed for absorption from an oral dose.) This model was chosen because, even though lipoprotein kinetics are usually analyzed using multicompartmental analysis, the use of this more complicated model did not improve the fit to the data. The mathematical expression used was:

$\mathrm{C}=\left(\mathrm{A} k_{i} / k_{i}-k_{d}\right)\left(\mathrm{e}^{-k_{d}}-\mathrm{e}^{-k_{i} t}\right)$

where $C$ is $d_{6}$-tocopherol concentration at time $t, A$ is estimate of the term FD/V where FD is the fraction of the dose absorbed and V is the apparent volume of distribution; $k_{i}$ is absorption rate constant; and $k_{d}$ is excretion rate constant. Estimates of $k_{d}$ were obtained by computing the slope from a logarithmic plot of the $d_{6}$-tocopherol concentration versus time (36-72 h) for each individual subject. These estimates were used as starting values to compute the parameters of the model, $\mathrm{A}, k_{i}$, and $k_{d}$, using the non-linear regression (NONLIN) procedure of SAS using the actual data. These parameters were then used to obtain the time at which the peak in the $\mathrm{d}_{6}$-tocopherol concentration occurred, $t_{\max }=\ln \left(k_{i} / k_{d}\right) /\left(k_{i}-k_{d}\right)$. Values of $t_{\max }$ were calculated for plasma and lipoprotein fractions from each individual.

\section{Results}

To determine whether the patients with familial isolated vitamin $\mathrm{E}$ deficiency could absorb dietary amounts of vitamin $\mathrm{E}$, patients and control subjects consumed a single dose of $d_{6}$-tocopherol with breakfast, then blood samples were drawn at the indicated intervals. The plasma and lipoprotein $d_{0}$ - and $d_{6}-\alpha-$ tocopherol concentrations at all time points for the individual subjects are presented in the Supplementary Table. The average plasma $d_{6}$-tocopherol concentrations, shown in Fig. 1, were found to change differently over time in patients and controls $(P<0.0001)$. To assess whether these differences were related to absorptive or to postabsorptive phenomena, the sta-

1. Abbreviations used in this paper: AUC, area under the curve; GLM, general linear models.

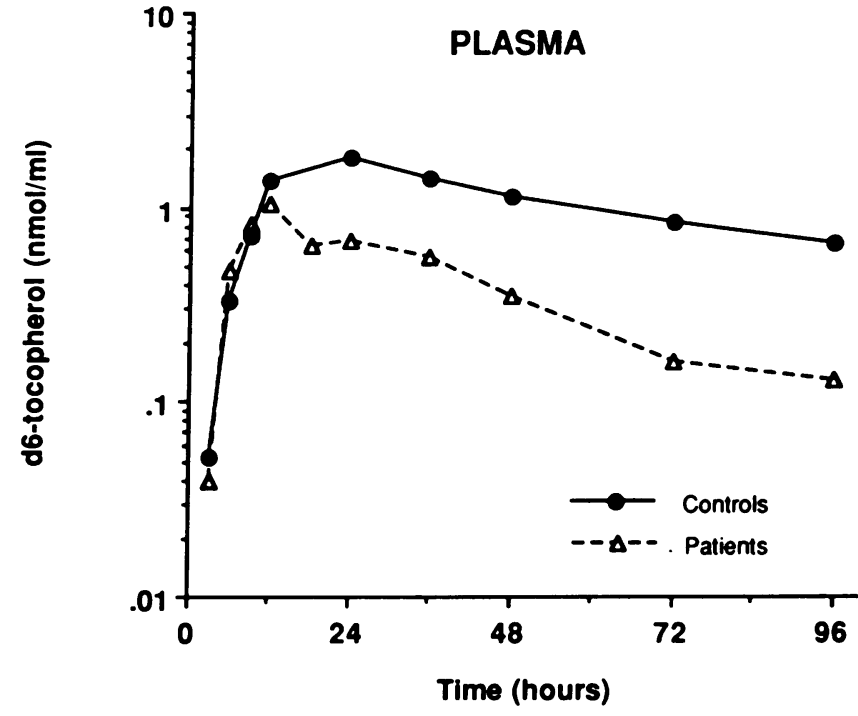

Figure 1. Average plasma $\mathrm{d}_{6}$-tocopherol concentrations. The mean concentrations of the plasma $d_{6}$-tocopherol $(\mathrm{nmol} / \mathrm{ml})$ from four patients with familial isolated vitamin $\mathrm{E}$ deficiency $(---\Delta---)$ and

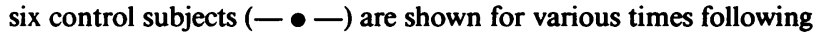
the oral administration of a single dose of $d_{6}$-tocopherol (amounts are shown in Table I). The standard deviations and statistical significance of the comparisons between controls and patients are given in Table II.

tistical significance of the differences between the two groups at each time point were determined (Table II). Both patients and controls had similar increases in their plasma $d_{6}$-tocopherol concentrations up to $12 \mathrm{~h}$, which has been shown to be the time interval of maximum triglyceride-rich lipoprotein secretion after a fat-rich meal (21). After the 12-h time point, the plasma $d_{6}$-tocopherol concentration began to decrease in the patients, while it continued to increase in the controls. During the 36-96-h period, it decreased in both groups with the patients having significantly lower $\mathrm{d}_{6}$-tocopherol concentrations (Fig. 1, Table II).

Plots of the average $d_{6}$-tocopherol concentrations in the four lipoprotein fractions isolated from patients and control subjects are shown in Fig. 2. Although the patients appear to have a smaller increase in the chylomicron $\mathrm{d}_{6}$-tocopherol concentrations than do the controls (Fig. $2 A$ ), this difference is not statistically significant (Table II). A two-factor analysis of variance, computed using the unbalanced design feature of GLM, comparing the chylomicron $\mathrm{d}_{6}$-tocopherol concentrations of the patients with that of controls was not significant. Furthermore, comparisons at each individual time point were not statistically different. The data in the Supplementary Table show that the range of chylomicron $\mathrm{d}_{6}$-tocopherol concentrations obtained in the control subjects encompassed that of the patients and that the patients had apparently higher concentrations of $d_{6}$-tocopherol at earlier time points than did the controls. The time at which the peaks in the $d_{6}$-tocopherol concentration occurred in the chylomicrons was also quite variable among the subjects. Other investigators have also observed this phenomenon when investigating the absorption of lipids and secretion of triglyceride-rich lipoproteins $(21,22)$.

The VLDL, LDL, and HDL $d_{6}$-tocopherol concentrations are shown in Fig. $2 B$, and $C$ and $D$, respectively. Up to $12 \mathrm{~h}$, 
Table II. $\left[d_{6}\right]$-Tocopherol in Lipoproteins and Plasma from Patients and Control Subjects

\begin{tabular}{|c|c|c|c|c|c|c|c|c|c|c|c|}
\hline Time & Patients & & Controls & & & Time & Patients & & Controls & & \\
\hline$n$ & mean $\pm S D$ & $n$ & mean $\pm S D$ & $n$ & $P$ & $n$ & mean $\pm S D$ & $n$ & mean $\pm S D$ & $n$ & $P$ \\
\hline \multicolumn{6}{|c|}{ Plasma $\left[\mathrm{d}_{6}\right]$-tocopherol $(\mathrm{nmol} / \mathrm{ml})$} & 24 & $0.17 \pm 0.07$ & 4 & $0.29 \pm 0.14$ & 6 & $<0.019$ \\
\hline 0 & $0.00 \pm 0.00$ & 4 & $0.00 \pm 0.00$ & 6 & $\mathbf{N S}^{*}$ & 36 & $0.14 \pm 0.06$ & 4 & $0.26 \pm 0.18$ & 6 & $<0.026$ \\
\hline 3 & $0.04 \pm 0.04$ & 3 & $0.05 \pm 0.05$ & 6 & NS & 48 & $0.10 \pm 0.07$ & 4 & $0.25 \pm 0.16$ & 6 & $<0.045$ \\
\hline 6 & $0.47 \pm 0.24$ & 4 & $0.33 \pm 0.37$ & 6 & NS & 72 & $0.04 \pm 0.04$ & 4 & $0.14 \pm 0.09$ & 6 & $<0.049$ \\
\hline 9 & $0.81 \pm 0.59$ & 4 & $0.72 \pm 0.44$ & 6 & NS & 96 & $0.01 \pm 0.02$ & 4 & $0.10 \pm 0.08$ & 6 & NS \\
\hline 12 & $1.05 \pm 0.42$ & 4 & $1.40 \pm 0.33$ & 6 & NS & \multirow{2}{*}{\multicolumn{6}{|c|}{ Interaction $P<0.008$}} \\
\hline 18 & $0.64 \pm 0.21$ & 4 & & & & & & & & & \\
\hline 24 & $0.66 \pm 0.42$ & 4 & $1.81 \pm 0.81$ & 6 & $<0.0001$ & \multicolumn{6}{|c|}{ LDL $\left[\mathrm{d}_{6}\right]$-tocopherol $(\mathrm{nmol} / \mathrm{ml}$ plasma) } \\
\hline 36 & $0.56 \pm 0.26$ & 4 & $1.45 \pm 0.58$ & 6 & $<0.0001$ & 0 & $0.01 \pm 0.01$ & 4 & $0.00 \pm 0.01$ & 6 & NS \\
\hline 48 & $0.35 \pm 0.22$ & 4 & $1.13 \pm 0.54$ & 6 & $<0.0003$ & 3 & $0.08 \pm 0.08$ & 4 & $0.01 \pm 0.03$ & 6 & NS \\
\hline 72 & $0.16 \pm 0.12$ & 4 & $0.84 \pm 0.26$ & 5 & $<0.0016$ & 6 & $0.23 \pm 0.12$ & 4 & $0.09 \pm 0.08$ & 6 & NS \\
\hline 96 & $0.11 \pm 0.07$ & 4 & $0.66 \pm 0.29$ & 6 & $<0.0095$ & 9 & $0.27 \pm 0.17$ & 4 & $0.21 \pm 0.15$ & 6 & NS \\
\hline \multicolumn{6}{|c|}{ Interaction $P<0.0001$} & 12 & $0.36 \pm 0.15$ & 4 & $0.47 \pm 0.17$ & 6 & NS \\
\hline Chyl & rons $\left[\mathrm{d}_{6}\right]$-toc & rol & $\mathrm{ol} / \mathrm{ml}$ plasm & & & 18 & $0.26 \pm 0.03$ & 3 & & & \\
\hline 0 & $0.00 \pm 0.00$ & 4 & $0.00 \pm 0.00$ & 6 & NS & 24 & $0.32 \pm 0.11$ & 4 & $0.72 \pm 0.25$ & 6 & $<0.0001$ \\
\hline 3 & $0.05 \pm 0.02$ & 3 & $0.02 \pm 0.02$ & 6 & NS & 36 & $0.23 \pm 0.09$ & 4 & $0.51 \pm 0.26$ & 6 & $<0.0020$ \\
\hline 6 & $0.06 \pm 0.03$ & 3 & $0.02 \pm 0.02$ & 6 & NS & 48 & $0.21 \pm 0.18$ & 4 & $0.52 \pm 0.21$ & 6 & $<0.0007$ \\
\hline 9 & $0.07 \pm 0.08$ & 4 & $0.14 \pm 0.13$ & 6 & NS & 72 & $0.08 \pm 0.03$ & 4 & $0.42 \pm 0.29$ & 6 & $<0.0002$ \\
\hline 12 & $0.08 \pm 0.04$ & 4 & $0.16 \pm 0.11$ & 6 & NS & \multirow{2}{*}{\multicolumn{6}{|c|}{ Interaction $P<0.0001$}} \\
\hline 18 & $0.05 \pm 0.02$ & 4 & & & & & & & & & \\
\hline 24 & $0.03 \pm 0.02$ & 3 & $0.04 \pm 0.03$ & 6 & NS & \multirow{2}{*}{\multicolumn{6}{|c|}{ HDL $\left[d_{6}\right]$-tocopherol $(\mathrm{nmol} / \mathrm{ml}$ plasma) }} \\
\hline 36 & $0.03 \pm 0.01$ & 4 & $0.05 \pm 0.04$ & 6 & NS & 0 & $0.00 \pm 0.01$ & 4 & $0.01 \pm 0.01$ & & \\
\hline 48 & $0.04 \pm 0.04$ & 3 & $0.03 \pm 0.01$ & 6 & NS & 3 & $0.06 \pm 0.06$ & 4 & $0.03 \pm 0.02$ & 6 & NS \\
\hline 72 & $0.02 \pm 0.01$ & 4 & $0.02 \pm 0.01$ & 6 & NS & 6 & $0.13 \pm 0.07$ & 4 & $0.10 \pm 0.07$ & 6 & NS \\
\hline \multirow[t]{2}{*}{96} & $0.02 \pm 0.02$ & 4 & $0.02 \pm 0.01$ & 5 & NS & 9 & $0.20 \pm 0.15$ & 4 & $0.24 \pm 0.14$ & 6 & NS \\
\hline & & & & \multicolumn{2}{|c|}{ Interaction NS } & 12 & $0.39 \pm 0.23$ & 4 & $0.48 \pm 0.16$ & 6 & NS \\
\hline \multicolumn{6}{|c|}{ VLDL $\left[\mathrm{d}_{6}\right]$-tocopherol (nmol/ml plasma) } & 18 & $0.27 \pm 0.07$ & 4 & & & \\
\hline 0 & $0.01 \pm 0.01$ & 4 & $0.00 \pm 0.01$ & 6 & NS & 24 & $0.20 \pm 0.02$ & 3 & $0.66 \pm 0.19$ & 6 & $<0.0001$ \\
\hline 3 & $0.11 \pm 0.08$ & 4 & $0.03 \pm 0.03$ & 6 & NS & 36 & $0.13 \pm 0.05$ & 3 & $0.56 \pm 0.21$ & 6 & $<0.0001$ \\
\hline 6 & $0.15 \pm 0.07$ & 4 & $0.08 \pm 0.07$ & 6 & NS & 48 & $0.13 \pm 0.06$ & 4 & $0.55 \pm 0.21$ & 6 & $<0.0001$ \\
\hline 9 & $0.15 \pm 0.04$ & 4 & $0.15 \pm 0.11$ & 6 & NS & 72 & $0.11 \pm 0.07$ & 4 & $0.34 \pm 0.10$ & 6 & $<0.0025$ \\
\hline 12 & $0.25 \pm 0.10$ & 4 & $0.24 \pm 0.06$ & 6 & NS & 96 & $0.07 \pm 0.06$ & 4 & $0.40 \pm 0.28$ & 6 & $<0.0001$ \\
\hline 18 & $0.14 \pm 0.08$ & 4 & & & & & & & & \multicolumn{2}{|c|}{ Interaction $P<0.0001$} \\
\hline
\end{tabular}

* NS, not significantly different.

the $d_{6}$-tocopherol concentrations of these fractions increased similarly in both the patients and controls with somewhat greater increases observed in the patients at the earlier time points, but after the 12-h time point statistically significant differences were found between patients and controls in all three of these lipoprotein fractions (Table II). At $24 \mathrm{~h}$ the $\mathrm{d}_{6}$-tocopherol concentration had decreased in all three fractions in the patients, while it had increased in the controls. From 36 to $96 \mathrm{~h}$ the $d_{6}$-tocopherol concentrations decreased in both groups with significantly lower concentrations observed in the patients. The patterns of changes observed in these lipoprotein fractions were similar to those observed in whole plasma.

It should be noted that the decay portion of the curves for the averages of the $d_{6}$-tocopherol in plasma (Fig. 1) and in the VLDL, LDL, and HDL fractions (Fig. 2, $B-D$ ) were steeper in the patients than in the controls. The $k_{d}$ values, calculated from the kinetic model for each individual subject, are shown in Table III. The patients had significantly greater $k_{d}$ values than did the controls in the plasma, LDL, and HDL fractions. The variability in the VLDL fraction resulted in too large an error factor for the comparison to be statistically significant, although three of the patients did have approximately twice as steep a slope as did the control subjects. The data in Table III emphasize that the patients had a more rapid loss of $d_{6}$-tocopherol from the plasma than did the controls.

One of the patients did not adhere to the protocol and failed to discontinue her vitamin $E$ supplements up until the time she received the $d_{6}$-tocopherol. The concentration of $d_{0}$ tocopherol in this patient's plasma decreased rapidly but the concentrations of $\mathrm{d}_{6}$-tocopherol in her plasma and lipoprotein fractions were similar to those in the other patients (cf. the Supplementary Table for patient 1 compared to patients 2-4). Furthermore, the rates of decrease of $d_{6}$-tocopherol in the plasma and lipoprotein fractions were similar to those of the other patients (Table III). Therefore, the presence or near ab- 

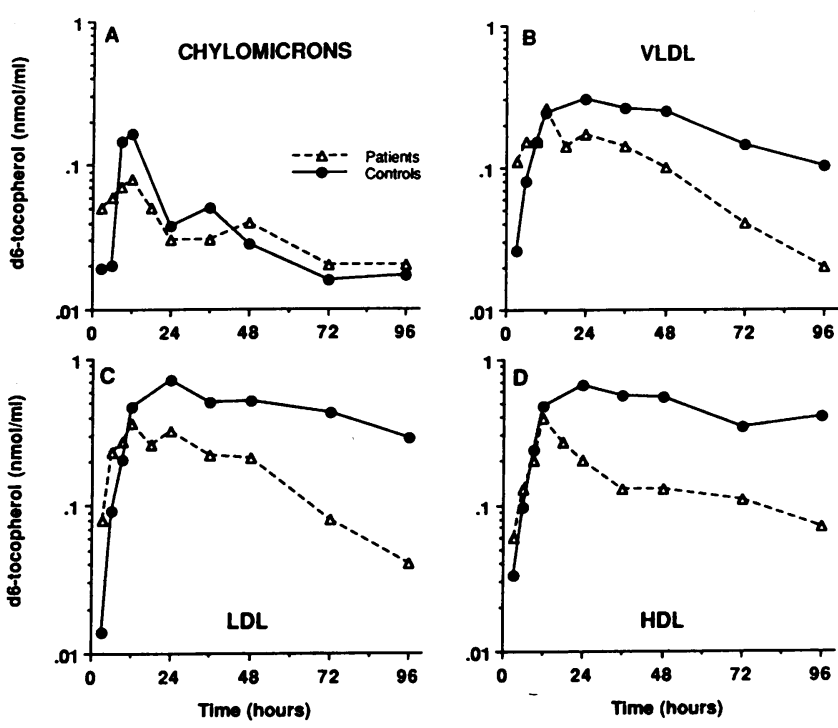

Figure 2. Lipoprotein $\mathrm{d}_{6}$-tocopherol concentrations. The time dependence of the mean $\mathrm{d}_{6}$-tocopherol concentrations ( $\mathrm{nmol} / \mathrm{ml} \mathrm{plasma)}$ for each of the lipoprotein fractions isolated from the plasma of patients (- - $\Delta---)$ and control subjects $(-\bullet-)$ following the oral administration of a single dose of $d_{6}$-tocopherol are shown. The statistical significance of the comparisons between controls and patients for each lipoprotein fraction are given in Table II. $(A)$ chylomicrons $(d<1.006 \mathrm{~g} / \mathrm{ml}),(B) \operatorname{VLDL}(d<1.006),(C) \operatorname{LDL}(1.006<d$ $<1.063)$, and $(D)$ HDL $(d>1.063)$.

sence of (unlabeled) vitamin $E$ in the plasma has no observable effect on the absorption or transport of the new, labeled vita$\min \mathrm{E}$.

The AUC obtained by plotting the $\mathrm{d}_{6}$-tocopherol concentration against time (0-96 h) was calculated for the plasma and lipoprotein fractions of each individual subject (Table IV). The AUCs of the chylomicron $\mathrm{d}_{6}$-tocopherol were not different for the two groups, while the AUC of the plasma $d_{6}$-tocopherol in the control subjects was nearly three times that of the patients and reflects differences in the AUCs obtained for $d_{6}$-tocoph- erol in VLDL, LDL, and HDL. The VLDL $\mathrm{d}_{6}$-tocopherol AUC was not statistically different between patients and controls, possibly because of contamination of VLDL by chylomicron remnants at the early time points, which would lead to elevated $d_{6}$-tocopherol concentrations in the VLDL fraction (see Discussion).

The $t_{\max }$ values, the time at which the peak in the $\mathrm{d}_{6}$-tocopherol concentration occurred, were estimated from the kinetic model. The plasma $t_{\max }$ in the patients occurred at a much earlier time than did that of the controls $(12 \pm 5 \mathrm{~h}$ compared with $21 \pm 6$ ) (Fig. 3). The chylomicron $\mathrm{d}_{6}$-tocopherol $t_{\max }$ values were not significantly different in patients and controls. Furthermore, the $t_{\max }$ values of all the lipoprotein fractions and the plasma in the patients were not statistically different from that of the chylomicrons. This was not the case in the controls for whom $t_{\max }$ values are significantly greater in VLDL, LDL, and HDL, than in the chylomicrons.

\section{Discussion}

The unimpaired absorption, but defective incorporation into VLDL, of dietary amounts of vitamin $E$ in four patients with familial isolated vitamin $\mathrm{E}$ deficiency has been demonstrated in this study. The adequacy of tocopherol absorption was demonstrated by $(a)$ the similar chylomicron $\mathrm{d}_{6}$-tocopherol concentrations in patients and controls, and $(b)$ the similar increases in the $d_{6}$-tocopherol concentrations in plasma and all of the lipoprotein fractions during the first $12 \mathrm{~h}$ of the study (Table II). Defective incorporation of $d_{6}$-tocopherol into VLDL was demonstrated by the differences in the times at which the $d_{6}$-tocopherol reached a maximum value in the plasma and each lipoprotein fraction. In the patients the $t_{\max }$ values were all similar and were similar to the chylomicron $t_{\max }$, whereas in the controls the $t_{\max }$ values increased in the order: chylomicrons $<$ VLDL $\leq$ LDL $\sim$ HDL (Fig. 3).

We have previously described a mechanism for the incorporation and transport of vitamin $E$ in plasma lipoproteins in normal subjects (10). Vitamin $E$ is secreted by the intestine in chylomicrons $(23,24)$, which subsequently undergo lipolysis

Table III. Estimates of $k_{d}$ Values $\left(h^{-1}\right)$ Calculated from the Kinetic Model for Patients and Controls

\begin{tabular}{llllrl}
\hline \multicolumn{1}{c}{ Subject } & Chylomicrons & VLDL & LDL & HDL & Plasma \\
\hline 1 Patient & -0.134 & -0.080 & -0.066 & -0.050 & -0.051 \\
2 Patient & $*$ & -0.007 & -0.024 & -0.039 & -0.060 \\
3 Patient & -0.123 & -0.073 & -0.037 & -0.032 & -0.084 \\
4 Patient & -0.670 & -0.209 & -0.080 & -0.060 & $-0.058 \pm 0.019$ \\
Mean \pm SD & $-0.309 \pm 0.313$ & $-0.092 \pm 0.084$ & $-0.052 \pm 0.026$ & $-0.047 \pm 0.014$ & -0.021 \\
5 Control & $*$ & -0.019 & -0.026 & -0.016 & $*$ \\
6 Control & -0.141 & -0.016 & -0.010 & -0.016 & -0.024 \\
7 Control & -0.479 & -0.080 & -0.022 & -0.014 & -0.048 \\
8 Control & -0.079 & -0.037 & -0.026 & -0.028 & -0.019 \\
9 Control & -0.207 & -0.056 & -0.031 & -0.028 & -0.020 \\
10 Control & -0.359 & -0.023 & -0.026 & $-0.020 \pm 0.007$ & $-0.026 \pm 0.011$ \\
Mean \pm SD & $-0.253 \pm 0.164$ & $-0.039 \pm 0.025$ & $-0.024 \pm 0.007$ & $<0.01$ & $<0.008$ \\
Patients vs. controls, $P<$ & NS & NS & $<0.03$ & & $<$ \\
\end{tabular}

* Data did not fit the model. 
Table IV. AUC of the Plasma and Lipoprotein $d_{6}$-Tocopherol Concentrations in Patients and Controls

\begin{tabular}{lccccc}
\hline & Plasma & Chylomicrons & VLDL & LDL & HDL \\
\hline Patients & $37 \pm 18$ & $4 \pm 2$ & $9 \pm 3$ & $17 \pm 6$ & $13 \pm 4$ \\
Controls & $101 \pm 35$ & $4 \pm 1$ & $18 \pm 9$ & $42 \pm 7$ & $44 \pm 16$ \\
$P$ & $<0.04$ & NS & $<0.10$ & $<0.02$ & $<0.006$
\end{tabular}

The mean $\pm \mathrm{SD}$ of the AUC $(\mathrm{nmol} \cdot \mathrm{h}$ per $\mathrm{ml})$ were calculated using the trapezoidal rule of the $d_{6}$-tocopherol concentrations in the plasma and lipoprotein fractions for each individual subject. Also shown are the results of the statistical comparisons between patients and controls.

in the circulation by lipoprotein lipase forming chylomicron remnants (25). Remnants are taken up by the liver, which then secretes the newly absorbed dietary lipids in nascent VLDL (26). The secretion of tocopherol in nascent VLDL has been demonstrated in intact rats and in isolated rat hepatocytes $(27,28)$.

Tocopherol appears to be transferred to other lipoproteins during catabolism of both chylomicrons and VLDL. This process could occur at several steps during triglyceride-rich lipoprotein catabolism. The HDL tocopherol could increase during the hydrolysis of triglyceride in chylomicrons and VLDL by lipoprotein lipase because apolipoproteins and surface components exchange between these lipoproteins and HDL (26). The LDL tocopherol could increase when circulating

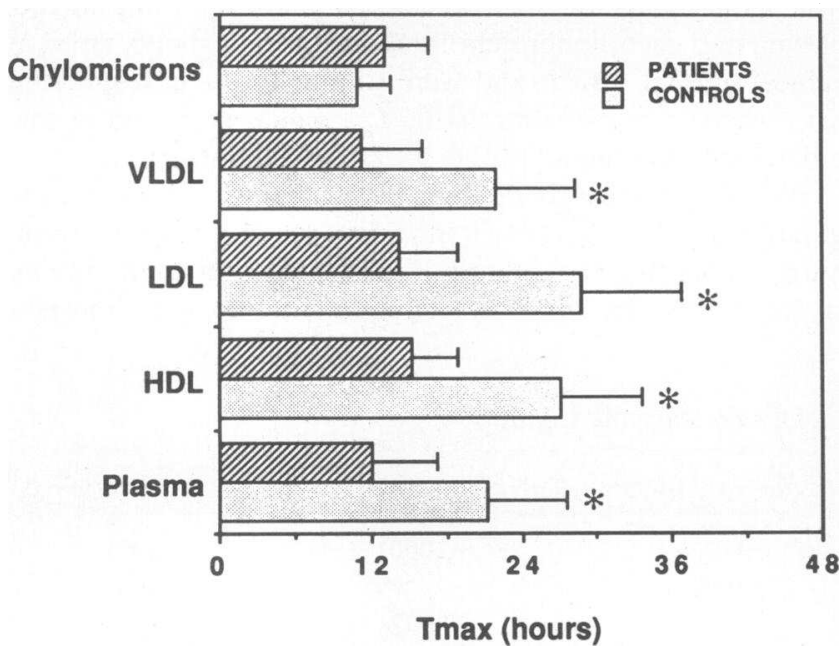

Figure 3. Time of maximum $\mathrm{d}_{6}$-tocopherol concentration. The mean $\pm \mathrm{SD}$ of the $t_{\max }$ (hours, calculated from the kinetic model) of the $d_{6}$-tocopherol concentrations in the plasma and indicated lipoprotein fractions are shown for each individual subject (patients $n$ $=4$, except VLDL, LDL $n=3$; controls $n=6$, except chylos, HDL $n=5$; values of $t_{\max }$ were omitted when the estimates from the kinetic model were $>2$ SD of the means. ${ }^{*}$ The comparisons between the patients and the controls were statistically different. The $P$-values of the comparisons are: chylomicrons, not significantly different, VLDL $P<0.04$, LDL $P<0.02$, HDL $P<0.01$, plasma $P<0.04$. In the patients the $t_{\max }$ values of the other lipoproteins were not significantly different from that of the chylomicrons. In the controls the chylomicrons versus VLDL, LDL, or HDL $P<0.05$; VLDL vs. LDL or HDL were not significantly different.
VLDL are converted by lipoprotein lipase and hepatic triglyceride lipase to form LDL. Since tocopherol can also exchange rapidly (without plasma transfer proteins) between LDL and HDL (17), an increase in the tocopherol content of either LDL or HDL would result in the nearly simultaneous increase in the tocopherol content of both lipoproteins, as was observed in our previous studies of vitamin $E$ transport (10).

The $t_{\max }$ values of the lipoprotein $\mathrm{d}_{6}$-tocopherol concentrations in the control subjects supports the concept of tocopherol transport from the intestine to the liver with the maximal secretion of tocopherol into the plasma dependent upon secretion from the liver. There were no significant differences between the patients and the controls in the $t_{\max }$ of the chylomicron $\mathrm{d}_{6}$-tocopherol, but the $t_{\max }$ values of the other lipoproteins and the plasma were significantly different. The chylomicron $t_{\max }$ reflects intestinal absorption and documents that the patients have no defect in vitamin $\mathrm{E}$ absorption. The catabolism of the chylomicrons occurs during the absorption phase, with uptake of the labeled tocopherol by the hepatocytes (via remnant uptake). The tocopherol is then secreted into VLDL in normal subjects, resulting in a later peak of $d_{6}$-tocopherol in VLDL and the other lipoprotein fractions. The peak in the plasma $d_{6}$-tocopherol concentration of the control subjects occurred after the maximum in the chylomicrons, just as would be expected for resecretion of the newly absorbed tocopherol by the liver in VLDL. The inability of the liver to secrete tocopherol into the VLDL should result in $t_{\max }$ values of chylomicrons, the lipoproteins and the plasma at the same interval. Fig. 3 demonstrates that this is what occurred in the patients. The $d_{6}$-tocopherol concentration peaked first in the normal subjects in the chylomicron fraction, followed by the VLDL, LDL and HDL fractions. By contrast, the similar values of $t_{\max }$ for all of the lipoprotein fractions in the patients with familial isolated vitamin $\mathrm{E}$ deficiency suggests that the catabolism of the chylomicrons in the patients results in the nearly simultaneous labeling of all of the lipoprotein fractions, that the chylomicron remnants containing $d_{6}$-tocopherol are then taken up by the liver, and that the subsequent resecretion by the liver of absorbed $d_{6}$-tocopherol into VLDL is defective.

Even more severely impaired secretion of $d_{6}$-tocopherol into VLDL may be present in our patients than that shown if the methodological problems in isolating lipoproteins are taken into account. The chylomicrons and VLDL were separated on the basis of their flotation characteristics. Chylomicrons, by definition, are large, triglyceride rich lipoproteins containing apolipoprotein B48 and are secreted only by the intestine (26). VLDL are also large, triglyceride rich lipoproteins, but contain apolipoprotein B100 and are secreted by the liver (26). The ultracentrifugation separation techniques used in this study do not distinguish between "small chylomicrons," "chylomicron remnants" and "large VLDL." Thus, the VLDL fractions collected at the early time points $(<12 \mathrm{~h})$ may contain a large number of chylomicron-derived particles. Studies are underway using affinity chromatography to identify the forms of apolipoprotein B associated with the triglyceride-rich lipoproteins.

An alternative explanation for the high levels of VLDL tocopherol observed in the patients at the early time points is an exchange mechanism. Although the tocopherol present in chylomicrons does not easily exchange $(15,16)$, during the hydrolysis of the chylomicrons and transfer of excess surface 
components to HDL particles an appreciable amount of the $d_{6}$-tocopherol could be transferred to the HDL with the possibility that the HDL subsequently transfers tocopherol to the VLDL in the circulation. VLDL has been shown to be an acceptor of tocopherol from HDL in vitro (17). This would be a nonspecific mechanism for the transfer of tocopherol to the VLDL, dependent on a high rate of transfer from chylomicrons to HDL during chylomicron catabolism. Since the peak in the $d_{6}$-tocopherol concentrations occurred simultaneously in all of the lipoprotein fractions of the patients, the precise mechanism for the increase in the $\mathrm{d}_{6}$-tocopherol content of the VLDL cannot be determined with certainty.

Previously, this disorder has been suggested to result from a selective defect in vitamin $\mathrm{E}$ absorption (5). However, in that study the only test of absorption was the measurement of plasma levels of tocopherol after a 2-g dose of $\alpha$-tocopheryl acetate. Similar to the results of the oral vitamin $E$ tolerance test carried out in the four patients studied here (8), the plasma tocopherol levels in the patient described by Harding et al. (5) were found to increase to normal levels after 4 hours and remained elevated for $24 \mathrm{~h}$. It is our contention that the absorption and secretion of tocopherol in chylomicrons is not impaired in these patients and that the catabolism of chylomicrons following a large oral dose of vitamin $\mathrm{E}$ will provide the other plasma lipoproteins with tocopherol. However, if the dose of vitamin $\mathrm{E}$ is small, similar to dietary levels or the amounts fed in the present study, the amounts of tocopherol distributed to the lipoproteins during chylomicron catabolism is insufficient to maintain the plasma tocopherol at normal levels. Although the patients absorb tocopherol when they consume a diet containing vitamin $\mathrm{E}$, and no vitamin $\mathrm{E}$ supplements, we suggest that the amounts that remain in the plasma are minuscule because the major route for tocopherol export from the liver into the plasma via VLDL is impaired. The $k_{\mathrm{d}}$ rates shown in Table III also lend further support for this hypothesis. The patients, who do not have the capability to maintain plasma tocopherol levels via the proposed VLDL mechanism, have a faster rate of disappearance than do the control subjects.

This faster rate of disappearance from the plasma also results from the inability of the patients to incorporate tocopherol into VLDL. As discussed above HDL could exchange with triglyceride-rich lipoproteins transferring tocopherols to these lipoproteins, which are then taken up by the liver via the apo $\mathrm{E}$ receptor. Thus, vitamin $\mathrm{E}$ from the peripheral tissues or from chylomicron catabolism, which is exchanged onto $\mathrm{HDL}$, is then exchanged back onto triglyceride-rich lipoproteins. Since these lipoproteins have a relatively short half-life compared with LDL or HDL, and are taken up by the liver, this results in a net transfer of tocopherol from the periphery to the liver. If the mechanism for secretion of tocopherol from the liver is impaired in the patients, then tocopherol would move from the plasma to liver to be sequestered and/or excreted. The inability of the liver to secrete tocopherol in VLDL would lead not only to a lower initial plasma tocopherol level, but also to a faster disappearance of vitamin E from the plasma. Plasma levels of vitamin $\mathrm{E}$ are also dependent upon slowly turning over pools (Burton, G. W., and K. U. Ingold, unpublished observations), but in the short time interval of this experiment these play a relatively unimportant role for the comparison between patients and controls.
To evaluate these data with respect to relevant information concerning catabolism of tocopherol we have surveyed the literature. Unfortunately, the nature of the major catabolic products of tocopherol are not known, nor is there much information on the measurement of the rates of disappearance or decay. In a very early study on the role of vitamin $E$ in humans Horwitt et al. (29) placed males on a sharply reduced intake of vitamin $\mathrm{E}$ in a controlled diet. Plasma levels measured at monthly intervals fell very slowly, perhaps by $15 \%$ at the end of the second month and by $40 \%$ by the end of the first year. These findings suggest conservation of plasma vitamin $E$, or maintenance of the level by release of tissue stores of tocopherol. The only tissue measured was red blood cells, and presumably the tocopherol levels in these cells is in equilibrium with plasma levels.

Patients with familial isolated vitamin E deficiency require $800 \mathrm{mg}$ of supplemental vitamin E per day to achieve maintenance plasma levels that are not strikingly different from those in normal subjects taking an equivalent supplement. However, it has been observed that even after prolonged periods of vitamin E supplementation with maintenance of normal plasma levels of tocopherol (and presumably adequate tissue levels), interruption of vitamin $E$ supplementation results in a plummeting of the plasma tocopherol levels in less than $72 \mathrm{~h}$ to values $<80 \%$ of maintenance levels. Our interpretation of these data is that there is no husbanding of tocopherol during passage through the liver and that since the mechanism for incorporation of tocopherol into VLDL is impaired the excretion into bile is complete and effective.

An alternative explanation for the observed altered clearance of plasma tocopherol in the patients might be a faster extrahepatic catabolism of vitamin $\mathrm{E}$. There are several reasons why we do not believe that the patients have a faster catabolism of vitamin E. (a) The vitamin E molecule might be more rapidly catabolized if the molecule were "abnormal", but humans do not synthesize the vitamin; thus a defective product which would be rapidly catabolized and excreted is not likely. (b) If the abnormality was, for example, a defective enzyme involved in vitamin $E$ catabolism, this would result more likely in an abnormal accumulation, not the disappearance, of vitamin E. (c) If the defect was a generalized more rapid oxidative process, one would expect to find other oxidized molecules accumulating in the plasma and tissues in addition to the rapid disappearance of vitamin $\mathrm{E}$, but this has not been found (8). (d) Finally, if a catabolic process were involved, one might expect that in the patient who had continued to take supplemental vitamin $E$, the $d_{6}$-tocopherol might be spared by the excess unlabeled tocopherol present in the plasma. However, this was not observed. The unlabeled tocopherol in this patient decreased rapidly, as did the $d_{6}$-tocopherol, which decreased at a rate similar to that in the other patients. When defined catabolic products can be measured in normal subjects and in patients, the issue of catabolism of tocopherol can be more clearly addressed. Taken together the available evidence suggests that the patients with familial isolated vitamin $\mathrm{E}$ deficiency are able to absorb vitamin $\mathrm{E}$, this is transported normally to the liver, but the tocopherol then may be sequestered, or excreted, and the normal incorporation of tocopherol in VLDL is defective.

We propose that the incorporation of tocopherol into VLDL by the liver requires a specific "tocopherol binding 
protein." This function fits with the known properties of the tocopherol binding protein isolated from rat liver cytosol (30-32). Further evidence for this mechanism in humans was demonstrated in our recent studies on the transport of $\alpha$ - and $\gamma$-tocopherols (33). Up to $12 \mathrm{~h}$ after oral administration of $1 \mathrm{~g}$ of each tocopherol, both tocopherols increased in the plasma of normal subjects, but by $24 \mathrm{~h}$ although the $\alpha$-tocopherol remained elevated, the $\gamma$-tocopherol concentration decreased. By contrast, lipoprotein lipase deficient subjects, who have a defective chylomicron clearance, had elevated levels of both tocopherols at $24 \mathrm{~h}$, while a subject with dysbetalipoproteinemia, who has a defective VLDL clearance, displayed the pattern of increased $\alpha$-tocopherol and decreased $\gamma$-tocopherol at $24 \mathrm{~h}$. These data suggest that all forms of tocopherol are transported in chylomicrons, but the subsequent secretion in VLDL is fairly specific for $\alpha$-tocopherol. The specificity of the incorporation of $\alpha$-tocopherol into VLDL suggests that a protein is involved. In the absence of such a protein or if the function of this protein were impaired, tocopherol might be more readily metabolized and/or excreted in bile instead of being secreted into the plasma in VLDL. We hypothesize that this purported liver protein is either absent or defective in the patients with familial isolated vitamin $\mathrm{E}$ deficiency resulting in impaired transport of vitamin $E$ to tissues other than the liver.

In conclusion, our data demonstrate that patients with familial isolated vitamin E deficiency absorb dietary amounts of $\alpha$-tocopherol. However, less of the absorbed vitamin $\mathrm{E}$ in these patients is incorporated into VLDL, LDL, and HDL than in the controls. The mechanism by which control subjects secrete $\alpha$-tocopherol from the liver appears defective in patients, and it is this inability to incorporate $\alpha$-tocopherol into VLDL that results in a faster rate of disappearance of tocopherol from the plasma. We hypothesize that a tocopherol binding protein, which has been described in rat liver, may play an important role in incorporating $\alpha$-tocopherol into VLDL, and may be absent or defective in these patients.

\begin{tabular}{|c|c|c|c|c|c|c|c|c|c|c|c|}
\hline \multirow[b]{2}{*}{ Subject } & \multirow[b]{2}{*}{ Time } & \multicolumn{2}{|c|}{ Plasma } & \multicolumn{2}{|c|}{ Chylomicrons } & \multicolumn{2}{|c|}{ VLDL } & \multicolumn{2}{|c|}{ LDL } & \multicolumn{2}{|c|}{ HDL } \\
\hline & & {$\left[d_{0}\right]$} & {$\left[d_{6}\right]$} & {$\left[\mathrm{d}_{0}\right]$} & {$\left[d_{6}\right]$} & {$\left[d_{0}\right]$} & {$\left[\mathrm{d}_{6}\right]$} & {$\left[\mathrm{d}_{0}\right]$} & {$\left[d_{6}\right]$} & {$\left[\mathrm{d}_{0}\right]$} & {$\left[\mathrm{d}_{6}\right]$} \\
\hline & $h$ & $\mathrm{nmol} / \mathrm{ml}$ & $\mathrm{nmol} / \mathrm{ml}$ & \multicolumn{8}{|c|}{ nmol/ml plasma } \\
\hline 1 & 0 & 32.45 & 0.00 & 0.52 & 0.00 & 6.86 & 0.00 & 12.36 & 0.00 & 10.92 & 0.00 \\
\hline 1 & 3 & 24.83 & 0.09 & 0.66 & 0.05 & 8.05 & 0.16 & 9.14 & 0.01 & 7.62 & 0.10 \\
\hline 1 & 6 & 21.79 & 0.32 & 0.36 & 0.05 & 5.66 & 0.12 & 8.17 & 0.20 & 6.70 & 0.08 \\
\hline 1 & 9 & 19.62 & 0.36 & 0.49 & 0.02 & 5.33 & 0.15 & 6.95 & 0.15 & 5.66 & 0.12 \\
\hline 1 & 12 & 18.59 & 0.89 & 0.38 & 0.12 & 3.93 & 0.25 & 5.20 & 0.25 & 4.73 & 0.30 \\
\hline 1 & 18 & 10.32 & 0.48 & 0.12 & 0.04 & 1.45 & 0.06 & 4.00 & 0.22 & 3.84 & 0.17 \\
\hline 1 & 24 & 8.18 & 0.36 & 0.06 & 0.01 & 1.93 & 0.14 & 3.33 & 0.16 & 3.06 & 0.18 \\
\hline 1 & 36 & 8.45 & 0.30 & 0.10 & 0.01 & 2.43 & 0.09 & 2.60 & 0.28 & 2.86 & 0.09 \\
\hline 1 & 48 & 6.66 & 0.15 & 0.10 & 0.00 & 1.47 & 0.05 & 2.62 & 0.08 & 2.28 & 0.10 \\
\hline 1 & 72 & 5.27 & 0.07 & 0.03 & 0.01 & 0.28 & 0.00 & 2.46 & 0.04 & 1.85 & 0.04 \\
\hline 1 & 96 & 4.80 & 0.07 & 0.04 & 0.05 & 0.58 & 0.01 & 1.30 & 0.00 & 1.84 & 0.02 \\
\hline 2 & 0 & 2.08 & 0.00 & 0.10 & 0.01 & 0.36 & 0.03 & 0.93 & 0.01 & 0.81 & 0.00 \\
\hline 2 & 3 & 2.11 & 0.04 & 0.13 & 0.03 & 0.25 & 0.03 & 1.95 & 0.14 & 0.78 & 0.03 \\
\hline 2 & 6 & 2.09 & 0.35 & & & 0.38 & 0.14 & 0.79 & 0.22 & 0.66 & 0.12 \\
\hline 2 & 9 & 1.83 & 0.41 & 0.05 & 0.04 & 0.28 & 0.10 & 0.76 & 0.20 & 0.72 & 0.21 \\
\hline 2 & 12 & 1.81 & 0.66 & 0.03 & 0.03 & 0.27 & 0.13 & 0.59 & 0.27 & 0.64 & 0.27 \\
\hline 2 & 18 & 2.03 & 0.65 & 0.09 & 0.06 & 0.51 & 0.15 & 0.73 & 0.27 & 0.65 & 0.31 \\
\hline 2 & 24 & 2.20 & 0.54 & 0.05 & 0.02 & 0.50 & 0.24 & 0.71 & 0.39 & 0.66 & 0.23 \\
\hline 2 & 36 & 2.33 & 0.49 & 0.09 & 0.04 & 0.55 & 0.23 & 0.66 & 0.26 & 0.59 & 0.19 \\
\hline 2 & 48 & 2.47 & 0.41 & 0.05 & 0.04 & 0.33 & 0.20 & 1.34 & 0.48 & 0.76 & 0.22 \\
\hline 2 & 72 & 2.60 & 0.11 & 0.16 & 0.03 & 0.38 & 0.09 & 0.88 & 0.10 & 0.92 & 0.19 \\
\hline 2 & 96 & 2.29 & 0.11 & 0.01 & 0.00 & 0.24 & 0.00 & 0.91 & 0.07 & 1.06 & 0.07 \\
\hline 3 & 0 & 1.75 & 0.00 & 0.04 & 0.00 & 0.29 & 0.02 & 0.51 & 0.03 & 0.38 & 0.02 \\
\hline 3 & 3 & 2.24 & 0.00 & & & 0.35 & 0.05 & 0.63 & 0.02 & 0.67 & 0.00 \\
\hline 3 & 6 & 2.21 & 0.38 & 0.03 & 0.10 & 0.19 & 0.08 & 0.60 & 0.11 & 0.47 & 0.08 \\
\hline 3 & 9 & 2.35 & 1.64 & 0.05 & 0.04 & 0.28 & 0.15 & 0.79 & 0.52 & 0.61 & 0.41 \\
\hline 3 & 12 & 2.19 & 1.64 & 0.15 & 0.06 & 0.27 & 0.38 & 0.73 & 0.58 & 0.91 & 0.73 \\
\hline 3 & 18 & 1.42 & 0.94 & 0.03 & 0.03 & 0.17 & 0.24 & & & 0.30 & 0.33 \\
\hline 3 & 24 & 2.04 & 1.28 & 0.35 & 0.43 & 0.26 & 0.23 & 0.61 & 0.41 & & \\
\hline 3 & 36 & 2.06 & 0.91 & 0.03 & 0.03 & 0.19 & 0.15 & 0.48 & 0.29 & & \\
\hline 3 & 48 & 2.28 & 0.63 & 0.11 & 0.08 & 0.24 & 0.09 & 0.56 & 0.19 & 0.40 & 0.13 \\
\hline 3 & 72 & 2.10 & 0.33 & 0.02 & 0.02 & 0.19 & 0.06 & 0.53 & 0.11 & 0.36 & 0.12 \\
\hline 3 & 96 & 1.83 & 0.20 & 0.04 & 0.02 & 1.21 & 0.00 & 0.57 & 0.06 & 0.55 & 0.16 \\
\hline
\end{tabular}


Supplementary Table (Continued)

\begin{tabular}{|c|c|c|c|c|c|c|c|c|c|c|c|}
\hline \multirow[b]{2}{*}{ Subject } & \multirow[b]{2}{*}{ Time } & \multicolumn{2}{|c|}{ Plasma } & \multicolumn{2}{|c|}{ Chylomicrons } & \multicolumn{2}{|c|}{ VLDL } & \multicolumn{2}{|c|}{ LDL } & \multicolumn{2}{|c|}{ HDL } \\
\hline & & {$\left[\mathrm{d}_{0}\right]$} & {$\left[\mathrm{d}_{6}\right]$} & {$\left[d_{0}\right]$} & {$\left[d_{6}\right]$} & {$\left[d_{0}\right]$} & {$\left[\mathrm{d}_{6}\right]$} & {$\left[d_{0}\right]$} & {$\left[d_{6}\right]$} & {$\left[d_{0}\right]$} & {$\left[d_{6}\right]$} \\
\hline & $h$ & $\mathrm{nmol} / \mathrm{ml}$ & $n \mathrm{~mol} / \mathrm{ml}$ & \multicolumn{8}{|c|}{ nmol/ml plasma } \\
\hline 4 & 0 & 0.91 & 0.00 & 0.11 & 0.01 & 0.74 & 0.00 & 0.32 & 0.00 & 0.49 & 0.00 \\
\hline 4 & 3 & & & 0.08 & 0.07 & 0.57 & 0.19 & 0.34 & 0.17 & 0.32 & 0.12 \\
\hline 4 & 6 & 0.80 & 0.83 & 0.09 & 0.05 & 0.54 & 0.24 & 0.43 & 0.39 & 0.46 & 0.22 \\
\hline 4 & 9 & 1.01 & 0.85 & 0.11 & 0.19 & 0.25 & 0.20 & 0.17 & 0.21 & 0.30 & 0.08 \\
\hline 4 & 12 & 1.17 & 0.99 & 0.07 & 0.11 & 0.34 & 0.26 & 0.45 & 0.35 & 0.47 & 0.27 \\
\hline 4 & 18 & 0.85 & 0.51 & 0.12 & 0.06 & 0.22 & 0.12 & 0.30 & 0.28 & 0.40 & 0.26 \\
\hline 4 & 24 & 1.08 & 0.49 & 0.03 & 0.05 & 0.23 & 0.08 & 0.38 & 0.31 & 0.41 & 0.20 \\
\hline 4 & 36 & 1.38 & 0.56 & 0.24 & 0.04 & 0.38 & 0.10 & 0.63 & 0.10 & 0.43 & 0.12 \\
\hline 4 & 48 & 1.02 & 0.20 & 0.00 & 0.00 & 0.18 & 0.05 & 0.49 & 0.09 & 0.52 & 0.09 \\
\hline 4 & 72 & 1.21 & 0.12 & 0.12 & 0.02 & 0.24 & 0.02 & 0.50 & 0.06 & 0.43 & 0.07 \\
\hline 4 & 96 & 1.52 & 0.04 & 0.27 & 0.00 & 0.59 & 0.05 & 0.48 & 0.02 & 0.51 & 0.04 \\
\hline 5 & 0 & 20.78 & 0.00 & 0.07 & 0.00 & 1.13 & 0.00 & 3.79 & 0.00 & 5.20 & 0.01 \\
\hline 5 & 3 & 21.04 & 0.00 & 0.13 & 0.00 & 1.99 & 0.00 & 3.41 & 0.00 & 4.89 & 0.03 \\
\hline 5 & 6 & 20.34 & 1.05 & 0.29 & 0.00 & 2.45 & 0.19 & 2.61 & 0.18 & 4.13 & 0.20 \\
\hline 5 & 9 & 19.31 & 1.47 & 2.14 & 0.25 & 3.28 & 0.33 & 7.19 & 0.47 & 2.67 & 0.50 \\
\hline 5 & 12 & 15.95 & 1.30 & 0.50 & 0.07 & 2.03 & 0.24 & 7.90 & 0.71 & 9.37 & 0.69 \\
\hline 5 & 24 & 16.15 & 1.14 & 0.16 & 0.02 & 1.17 & 0.19 & 3.48 & 0.42 & 4.66 & 0.52 \\
\hline 5 & 36 & 18.67 & 1.20 & 0.56 & 0.07 & 7.06 & 0.33 & 7.70 & 0.51 & 7.99 & 0.46 \\
\hline 5 & 48 & 19.74 & 0.89 & 0.07 & 0.02 & 3.71 & 0.22 & 8.86 & 0.37 & 9.94 & 0.43 \\
\hline 5 & 72 & 20.40 & 0.86 & 0.13 & 0.01 & 3.03 & 0.17 & 8.43 & 0.24 & 10.00 & 0.36 \\
\hline 5 & 96 & 18.81 & 0.42 & 0.14 & 0.01 & 4.00 & 0.07 & 6.70 & 0.22 & 9.84 & 0.33 \\
\hline 6 & 0 & 38.73 & 0.00 & 0.54 & 0.00 & 2.91 & 0.00 & 11.69 & 0.00 & 10.59 & 0.00 \\
\hline 6 & 3 & 24.11 & 0.04 & 0.34 & 0.00 & 4.89 & 0.04 & 10.14 & 0.00 & 10.36 & 0.02 \\
\hline 6 & 6 & 25.21 & 0.06 & 0.31 & 0.02 & 4.02 & 0.02 & 10.78 & 0.04 & 10.02 & 0.07 \\
\hline 6 & 9 & 29.24 & 0.85 & 0.65 & 0.14 & 5.60 & 0.20 & 9.22 & 0.22 & 9.38 & 0.27 \\
\hline 6 & 12 & 29.13 & 1.08 & 0.34 & 0.03 & 3.48 & 0.27 & 9.66 & 0.43 & 10.72 & 0.42 \\
\hline 6 & 24 & 28.21 & 2.74 & 0.35 & 0.09 & 4.51 & 0.46 & 10.35 & 1.08 & 7.85 & 0.78 \\
\hline 6 & 36 & 28.55 & 2.37 & 1.13 & 0.12 & 6.20 & 0.59 & 8.81 & 0.86 & 8.69 & 0.83 \\
\hline 6 & 48 & 26.32 & 1.93 & 0.30 & 0.03 & 4.75 & 0.53 & 8.33 & 0.70 & 8.52 & 0.88 \\
\hline 6 & 72 & 27.39 & 1.19 & 0.33 & 0.03 & 3.94 & 0.29 & 9.10 & 1.00 & & \\
\hline 6 & 96 & 34.05 & 1.13 & 0.31 & 0.01 & 5.11 & 0.25 & 9.38 & 0.49 & 4.62 & 0.96 \\
\hline 7 & 0 & 32.41 & 0.00 & 0.22 & 0.00 & 1.40 & 0.00 & 9.00 & 0.00 & 11.49 & 0.00 \\
\hline 7 & 3 & 27.31 & 0.01 & 0.11 & 0.03 & 0.77 & 0.02 & 10.16 & 0.00 & 11.45 & 0.03 \\
\hline 7 & 6 & 25.24 & 0.14 & 0.14 & 0.00 & 1.99 & 0.03 & 5.50 & 0.04 & 9.66 & 0.04 \\
\hline 7 & 9 & 25.44 & 0.26 & 0.10 & 0.01 & 2.07 & 0.04 & 9.15 & 0.07 & 12.03 & 0.17 \\
\hline 7 & 12 & 26.48 & 1.78 & 0.43 & 0.21 & 2.24 & 0.27 & 6.86 & 0.53 & 9.98 & 0.59 \\
\hline 7 & 24 & 23.18 & 2.24 & 0.17 & 0.04 & 0.84 & 0.09 & 7.65 & 0.80 & 9.79 & 0.96 \\
\hline 7 & 36 & 25.65 & 1.57 & 0.34 & 0.02 & 2.04 & 0.13 & 8.99 & 0.61 & 10.53 & 0.71 \\
\hline 7 & 48 & 25.09 & 1.18 & 0.11 & 0.02 & 0.94 & 0.08 & 9.63 & 0.56 & 11.21 & 0.54 \\
\hline 7 & 72 & 28.45 & 0.85 & 0.12 & 0.00 & 1.18 & 0.05 & 8.90 & 0.34 & 11.44 & 0.47 \\
\hline 7 & 96 & 29.76 & 0.80 & 0.08 & 0.01 & 1.18 & 0.04 & 9.47 & 0.25 & 13.27 & 0.36 \\
\hline 8 & 0 & 23.13 & 0.00 & 1.74 & 0.00 & 0.95 & 0.00 & 7.51 & 0.03 & 8.37 & 0.03 \\
\hline 8 & 3 & 20.78 & 0.12 & 1.26 & 0.04 & 2.00 & 0.07 & 8.50 & 0.07 & 8.91 & 0.07 \\
\hline 8 & 6 & 22.24 & 0.28 & 0.40 & 0.02 & 2.23 & 0.15 & 9.20 & 0.21 & 9.40 & 0.17 \\
\hline 8 & 9 & 20.70 & 0.47 & 0.12 & 0.02 & 2.62 & 0.09 & 9.96 & 0.26 & 9.03 & 0.21 \\
\hline 8 & 12 & 20.44 & 1.69 & 0.51 & 0.29 & 2.07 & 0.29 & 8.30 & 0.53 & 8.39 & 0.53 \\
\hline 8 & 24 & 21.55 & 1.98 & 0.20 & 0.04 & 3.14 & 0.43 & 8.45 & 0.82 & 4.82 & 0.50 \\
\hline 8 & 36 & 20.82 & 1.51 & 0.30 & 0.05 & 1.81 & 0.15 & 7.51 & 0.48 & 7.73 & 0.50 \\
\hline 8 & 48 & 14.35 & 0.82 & 0.40 & 0.04 & 2.74 & 0.25 & 7.94 & 0.69 & 7.57 & 0.68 \\
\hline 8 & 72 & 19.63 & 0.71 & 0.22 & 0.01 & 1.27 & 0.15 & 6.78 & 0.31 & 8.93 & 0.38 \\
\hline 8 & 96 & 21.78 & 0.53 & 0.45 & 0.03 & 1.86 & 0.04 & 7.79 & 0.28 & 8.30 & 0.30 \\
\hline
\end{tabular}




\begin{tabular}{|c|c|c|c|c|c|c|c|c|c|c|c|}
\hline \multirow[b]{2}{*}{ Subject } & \multirow[b]{2}{*}{ Time } & \multicolumn{2}{|c|}{ Plasma } & \multicolumn{2}{|c|}{ Chylomicrons } & \multicolumn{2}{|c|}{ VLDL } & \multicolumn{2}{|c|}{ LDL } & \multicolumn{2}{|c|}{ HDL } \\
\hline & & {$\left[d_{0}\right]$} & {$\left[d_{6}\right]$} & {$\left[d_{0}\right]$} & {$\left[d_{6}\right]$} & {$\left[\mathrm{d}_{0}\right]$} & {$\left[\mathrm{d}_{6}\right]$} & {$\left[d_{0}\right]$} & {$\left[d_{6}\right]$} & {$\left[d_{0}\right]$} & {$\left[d_{6}\right]$} \\
\hline & $h$ & $\mathrm{nmol} / \mathrm{ml}$ & $\mathrm{nmol} / \mathrm{ml}$ & \multicolumn{8}{|c|}{ nmol/ml plasma } \\
\hline 9 & 0 & 45.36 & 0.00 & 1.24 & 0.00 & 3.28 & 0.00 & 15.37 & 0.00 & 19.76 & 0.00 \\
\hline 9 & 3 & 45.83 & 0.02 & 1.71 & 0.02 & 5.00 & 0.00 & 11.79 & 0.01 & 18.51 & 0.03 \\
\hline 9 & 6 & 37.38 & 0.08 & 0.87 & 0.05 & 8.65 & 0.04 & 10.96 & 0.06 & 17.16 & 0.04 \\
\hline 9 & 9 & 49.07 & 0.39 & 1.01 & 0.11 & 5.88 & 0.07 & 10.36 & 0.06 & 17.38 & 0.10 \\
\hline 9 & 12 & 41.20 & 0.98 & 0.86 & 0.10 & 3.82 & 0.11 & 4.59 & 0.20 & 14.77 & 0.24 \\
\hline 9 & 24 & 37.40 & 0.56 & 0.60 & 0.04 & 6.11 & 0.28 & 11.17 & 0.45 & 12.36 & 0.50 \\
\hline 9 & 36 & 42.89 & 0.57 & 0.61 & 0.02 & 9.77 & 0.14 & 5.23 & 0.05 & 15.39 & 0.22 \\
\hline 9 & 48 & 37.38 & 0.43 & 0.63 & 0.02 & 4.52 & 0.09 & 14.25 & 0.17 & 17.41 & 0.30 \\
\hline 9 & 72 & 37.28 & 0.42 & 1.02 & 0.02 & 3.93 & 0.08 & 13.81 & 0.21 & 15.96 & 0.20 \\
\hline 9 & 96 & 38.90 & 0.34 & 0.70 & 0.02 & 3.32 & 0.09 & 13.62 & 0.13 & 18.04 & 0.19 \\
\hline 10 & 0 & 23.20 & 0.00 & 1.47 & 0.00 & 5.58 & 0.02 & 10.25 & 0.00 & 9.23 & 0.00 \\
\hline 10 & 3 & 22.57 & 0.12 & 0.57 & 0.02 & 4.14 & 0.02 & 8.67 & 0.00 & 6.31 & 0.03 \\
\hline 10 & 6 & 23.34 & 0.36 & 0.35 & 0.02 & 4.78 & 0.06 & 8.30 & 0.02 & 7.38 & 0.05 \\
\hline 10 & 9 & 27.87 & 0.86 & 1.02 & 0.34 & 4.71 & 0.19 & 9.58 & 0.17 & 7.54 & 0.20 \\
\hline 10 & 12 & 25.95 & 1.56 & 1.36 & 0.28 & 2.57 & 0.25 & 8.67 & 0.42 & 7.42 & 0.39 \\
\hline 10 & 24 & 22.96 & 2.23 & 0.14 & 0.02 & 3.55 & 0.31 & 8.71 & 0.78 & 8.03 & 0.72 \\
\hline 10 & 36 & 22.48 & 1.50 & 0.21 & 0.02 & 3.04 & 0.21 & 5.77 & 0.55 & 9.24 & 0.66 \\
\hline 10 & 48 & 24.60 & 1.54 & 0.26 & 0.03 & 4.83 & 0.31 & 10.55 & 0.62 & 8.01 & 0.43 \\
\hline 10 & 72 & 18.46 & 0.99 & 0.46 & 0.03 & 3.00 & 0.12 & 11.32 & 0.44 & 7.69 & 0.29 \\
\hline 10 & 96 & 23.26 & 0.74 & & & 3.76 & 0.13 & 10.09 & 0.33 & 9.45 & 0.27 \\
\hline
\end{tabular}

\section{Acknowledgments}

We would like to express our appreciation to Michael Devereaux, Nora Lagmay, Ann C. Webb, and Eva Lusztyk, who provided excellent technical assistance, and the nursing staff of the Clinical Research Center, University of Colorado Health Science Center.

Dr. Traber and Dr. Kayden acknowledge the support of this work by grants from the National Heart Lung and Blood Institute (HL-30842) and the Natural Source Vitamin E association. Dr. Sokol was supported in part by U. S. Public Health Service grant RR-00069 from the General Clinical Research Centers Branch, Division of Research Resources, National Institutes of Health. Dr. Ingold and Dr. Burton thank the Association for International Cancer Research, the National Foundation for Cancer Research, Eastman Chemicals, Henkel Corporation, Eisai Company, and the Natural Source Vitamin E Association for financial support of this work.

\section{References}

1. Sokol, R. J. 1988. Vitamin E deficiency and neurologic disease. Annu. Rev. Nutr. 8:351-373.

2. Burck, U., H. H. Goebel, H. D. Kuhlendahl, C. Meier, and K. M. Goebel. 1981. Neuromyopathy and vitamin E deficiency in man. Neuropediatrics. 12:267-278.

3. Kohlschutter, A., C. Hubner, W. Jansen, and S. G. Lindner. 1988. A treatable familial neuromyopathy with vitamin $E$ deficiency, normal absorption, and evidence of increased consumption of vitamin E. J. Inher. Metab. Dis. 11:149-152.

4. Laplante, P., M. Vanasse, J. Michaud, G. Geoffroy, and P. Brochu. 1984. A progressive neurological syndrome associated with an isolated vitamin E deficiency. Can. J. Neurol. Sci. 11:561-564.

5. Harding, A. E., S. Matthews, S. Jones, C. J. K. Ellis, I. W. Booth, and D. P. R. Muller. 1985. Spinocerebellar degeneration associated with a selective defect of vitamin E absorption. N. Engl. J. Med. 313:32-35.

6. Krendel, D. A., J. M. Gilchrest, A. O. Johnson, and E. H. Bossen. 1987. Isolated deficiency of vitamin $E$ with progressive neurologic deterioration. Neurology. 37:538-540.

7. Yokota, T., Y. Wada, T. Furukawa, H. Tsukagoshi, T. Uchihara, and S. Watabiki. 1987. Adult-onset spinocerebellar syndrome with idiopathic vitamin E deficiency. Ann. Neurol. 22:84-87.

8. Sokol, R. J., H. J. Kayden, D. B. Bettis, M. G. Traber, H. Neville, S. Ringel, W. B. Wilson, and D. A. Stumpf. 1988. Isolated vitamin E deficiency in the absence of fat malabsorption-familial and sporadic cases: Characterization and investigation of causes. J. Lab. Clin. Med. 111:548-559.

9. Traber, M. G., R. J. Sokol, S. P. Ringel, H. E. Neville, C. A. Thellman, and H. J. Kayden. 1987. Lack of tocopherol in peripheral nerves of vitamin E-deficient patients with peripheral neuropathy. $N$. Engl. J. Med. 317:262-265.

10. Traber, M. G., K. U. Ingold, G. W. Burton, and H. J. Kayden. 1988. Absorption and transport of deuterium-substituted $2 R, 4^{\prime} R, 8^{\prime} R-$ $\alpha$-tocopherol in human lipoproteins. Lipids. 23:791-797.

11. Stumpf, D. A., R. Sokol, D. Bettis, H. Neville, S. Ringel, C. Angelini, and R. Bell. 1987. Freidreich's disease: V. Variant form with vitamin E deficiency and normal fat absorption. Neurology. 37:68-74.

12. Ingold, K. U., G. W. Burton, D. O. Foster, L. Hughes, D. A. Lindsay, and A. Webb. 1987. Biokinetics of and discrimination between dietary RRR- and SRR- $\alpha$-tocopherols in the male rat. Lipids. 22:163-172.

13. Ingold, K. U., L. Hughes, M. Slaby, and G. W. Burton. 1987. Synthesis of $2 R, 4^{\prime} R, 8^{\prime} R-\alpha$-tocopherols selectively labelled with deuterium. J. Labelled Comp. Radiopharm. 24:817-831.

14. Burton, G. W., K. U. Ingold, D. O. Foster, S. C. Cheng, A. Webb, L. Hughes, and E. Lusztyk. 1988. Comparison of free $\alpha$-tocopherol and $\alpha$-tocopheryl acetate as sources of vitamin $\mathrm{E}$ in rats and humans. Lipids. 23:834-840. 
15. Kayden, H. J., and L. K. Bjornson. 1972. The dynamics of vitamin E transport in the human erythrocyte. Ann. NY Acad. Sci. 203:127-140.

16. Bjornson, L. K., C. Gniewkowski, and H. J. Kayden. 1975. A comparison of the exchange of $\alpha$-tocopherol and of free cholesterol between rat plasma lipoproteins and erythrocytes. J. Lipid Res. 16:39-53.

17. Massey, J. B. 1984. Kinetics of transfer of $\alpha$-tocopherol between model and native plasma lipoproteins. Biochim. Biophys. Acta. 793:387-392.

18. SAS Institute, Inc. 1985. "SAS User's Guide: Statistics." SAS Institute Inc., Gary, NC.

19. Harvey, W. R. 1975. Least-squares Analysis of Data with Unequal Subclass Numbers. USDA Report ARS. H-4.

20. Gibaldi, M., and D. Perrier. 1982. Pharmacokinetics. Marcel Dekker, Inc., New York.

21. Cohn, J. S., J. R. McNamara, S. D. Cohn, J. M. Ordovas, and E. J. Schaefer. 1988. Postprandial plasma lipoprotein changes in human subjects of different ages. J. Lipid Res. 29:469-479.

22. Cohn, J. S., J. R. McNamara, S. D. Cohn, J. M. Ordovas, and E. J. Schaefer. 1988. Plasma apolipoprotein changes in the triglyceride-rich lipoprotein fraction of human subjects fed a fat-rich meal. $J$. Lipid Res. 29:925-936.

23. Bjorneboe, A., G. E. A. Bjorneboe, E. Bodd, B. F. Hagen, N. Kveseth, and C. A. Drevon. 1986. Transport and distribution of $\alpha$-tocopherol in lymph, serum and liver cells in rats. Biochim. Biophys. Acta. 889:310-315.

24. Traber, M. G., H. J. Kayden, J. B. Green, and M. H. Green.
1986. Absorption of water miscible forms of vitamin $E$ in a patient with cholestasis and in rats. Am. J. Clin. Nutr. 44:914-923.

25. Nelsson-Ehle, P., A. S. Garfinkel, and M. C. Schotz. 1980. Lipolytic enzymes and plasma lipoprotein metabolism. Annu. Rev. Biochem. 49:667-693.

26. Gotto, A. M., H. J. Pownall, and R. J. Havel. 1986. Introduction to the Plasma Lipoproteins. Plasma Lipoproteins, Part A: Preparation, Structure and Molecular Biology. J. Segrest and J. Albers, editors. Academic Press, Inc., Orlando, FL.3-41.

27. Cohn, W., F. Loechleiter, and F. Weber. 1988. $\alpha$-Tocopherol is secreted from rat liver in very low density lipoproteins. J. Lipid Res. 29:1359-1366.

28. Bjorneboe, A., G. E. A. Bjorneboe, B. F. Hagen, J. O. Nossen, and C. A. Drevon. 1987. Secretion of $\alpha$-tocopherol from cultured rat hepatocytes. Biochim. Biophys. Acta. 922:199-205.

29. Horwitt, M. K., C. C. Harvey, G. D. Duncan, and W. C. Wilson. 1956. Effects of limited tocopherol intake in man with relationships to erythrocyte hemolysis and lipid oxidations. Am. J. Clin. Nutr. 4:408-419.

30. Catignani, G. L., and J. G. Bieri. 1977. Rat liver $\alpha$-tocopherol binding protein. Biochim. Biophys. Acta. 497:349-357.

31. Murphy, D. J., and R. D. Mavis. 1981. Membrane transfer of $\alpha$-tocopherol. J. Biol. Chem. 256:10464-10468.

32. Behrens, W. A., and R. Madere. 1982. Transfer of $\alpha$-tocopherol to microsomes mediated by a partially purified liver $\alpha$-tocopherol binding protein. Nutr. Res. 2:611-618.

33. Traber, M. G., and H. J. Kayden. 1989. Preferential incorporation of alpha tocopherol compared with gamma tocopherol in human lipoproteins. Am. J. Clin. Nutr. 49:517-526. 